OPEN ACCESS

Edited by:

Trevor Edmund Angell, University of Southern California, United States

Reviewed by: Zhihong Wang,

China Medical University, China Wendy Sacks, Cedars Sinai Medical Center. United States

${ }^{*}$ Correspondence: Weiping Teng twp@vip.163.com

Specialty section: This article was submitted to Thyroid Endocrinology, a section of the journal Frontiers in Endocrinology

Received: 03 March 2021 Accepted: 07 June 2021 Published: 12 July 2021

Citation: Zhang F, Zheng B, Yu X, Wang X, Wang $S$ and Teng $W(2021)$

Risk Factors for Contralateral Occult Carcinoma in Patients With

Unilateral Papillary Thyroid

Carcinoma: A Retrospective

Study and Meta-Analysis.

Front. Endocrinol. 12:675643. doi: 10.3389/fendo.2021.675643

\section{Risk Factors for Contralateral Occult Carcinoma in Patients With Unilateral Papillary Thyroid Carcinoma: A Retrospective Study and Meta-Analysis}

\author{
Fan Zhang ${ }^{1}$, Boyuan Zheng ${ }^{2}$, Xiaohui Yu ${ }^{1}$, Xichang Wang ${ }^{1}$, Shiwei Wang ${ }^{1}$ \\ and Weiping Teng ${ }^{1 *}$
}

${ }^{1}$ Department of Endocrinology and Metabolism, Institute of Endocrinology, National Health Commission Key Laboratory of Diagnosis and Treatment of Thyroid Diseases, The First Hospital of China Medical University, Shenyang, China, ${ }^{2}$ Department of Thyroid Surgery, The First Hospital of China Medical University, Shenyang, China

Background: Bilateral lesions are common in papillary thyroid carcinoma (PTC). For patients with unilateral PTC, occult carcinoma that is not detected preoperatively, but pathologically after surgery, might remain in the contralateral lobe. In this situation, inadequate surgical extent could cause relapse and even lead to re-operation. Here, we explore the frequency and investigate the risk factors of contralateral occult PTC in unilateral PTC through a retrospective study conducted by our team and published articles online, respectively.

Methods: We collected the patients' clinical data in our hospital, whose cancer was determined to be confined to the unilateral lobe by preoperative image examination ( $\mathrm{N}=$ 204). These patients underwent initially total or near-total thyroidectomy and included their clinical data in the meta-analysis. We searched related literature in the PubMed, Embase, MEDLINE, Cochrane, and Web of Science databases until December 7, 2020, in order to perform a meta-analysis. The relevant articles were examined and the eligible studies were included to assess the association between clinicopathologic factors and contralateral occult PTC.

Results: The meta-analysis included nine studies (involving 4347 patients). Of these, eight studies were from the databases, and one study was our retrospective data. The meta-analysis showed that the prevalence of contralateral occult PTC was $26.6 \%$ in all patients. A tumor size $>1 \mathrm{~cm}$, ipsilateral multifocality, contralateral benign nodule, and central lymph node metastasis were significantly associated with contralateral occult PTC. In contrast, sex, age, ETE, capsular invasion, BRAF mutation, Hashimoto thyroiditis, and lateral lymph node metastasis were insignificantly associated with contralateral occult PTC. 
Conclusion: The meta-analysis identified a tumor size $>1 \mathrm{~cm}$, ipsilateral multifocality, contralateral benign nodule, and CLNM as being significant risk factors for contralateral occult PTC. These findings may guide the extent of surgery in unilateral PTC patients.

Keywords: contralateral, meta-analysis, occult, papillary thyroid carcinoma, risk factors

\section{INTRODUCTION}

Thyroid carcinoma is the most frequent endocrine malignancy, accounting for approximately $2.9 \%$ of all newly diagnosed cancer (1). Its incidence has increased from 5.7 to 14.7 per 100,000 people over the past two decades (2). Papillary thyroid carcinoma (PTC), medullary thyroid carcinoma, follicular thyroid carcinoma, and anaplastic thyroid carcinoma are the four main types of thyroid carcinoma. PTC is the most common thyroid cancer type, accounting for approximately $80.0 \%$ of malignant thyroid tumors (3). In addition, papillary thyroid microcarcinoma (PTMC) is classified to PTC. According to the histological classification of thyroid tumors by the World Health Organization, PTMC is defined as tumors with a maximum size of $10 \mathrm{~mm}$ or smaller. PTC has an excellent prognosis, with the main treatment being surgical resection. The overall survival rate has remained between $90 \%$ and $96 \%$ in recent decades $(4,5)$.

Despite advances in the understanding of the underlying biological characteristics of PTC and the development of evidence-based guidelines for its treatment, the adequate extent of surgical management (lobectomy vs. total thyroidectomy) of PTC is still a matter of debate. Neck ultrasound (US) and USguided fine-needle aspiration (FNA) are currently used in decision making for the surgical management of PTC. However, despite that high-resolution US can detect foci as small as $2 \mathrm{~mm}$ (6), smaller tumors remain undetected. Occult carcinoma is defined as a tumor that is not detected preoperatively but pathologically after surgery. As reported, PTC frequently occurs as multifocal or bilateral lesions, with the prevalence of multifocality ranging from $20.0 \%$ to $36.1 \%$ (79). The 2015 American Thyroid Association Guidelines (10) endorse thyroid lobectomy (TL) as an initial surgical approach for low risk, small- to medium-sized (T1-T2), N0 PTC in the absence of an extrathyroidal extension (ETE). For PTCs detected preoperatively in bilateral lobes, there is no controversy in performing total thyroidectomy (TT). Contralateral occult PTC is a specific subtype of bilateral multifocal PTC. It has been reported that the rate of occult PTC in the contralateral lobe ranges from $12 \%$ to $40 \%$ (11-13). For contralateral occult PTC, TL may be insufficient and could cause relapse and even lead to re-operation, which brings higher risks. Therefore, identifying risk factors of contralateral occult PTC could help surgeons to determine the optimal scope of surgery, but there is a limited

Abbreviations: PTC, papillary thyroid carcinoma; CLNM, central lymph node metastasis; ETE, extrathyroidal extension; HT, Hashimoto thyroiditis; LLNM, lateral lymph node metastasis; TC, thyroid carcinoma; PTMC, papillary thyroid microcarcinoma; WHO, World Health Organization; US, neck ultrasound; FNA, fine-needle aspiration; TL, thyroid lobectomy; TT, total thyroidectomy; SD, standard deviations; CIs, confidence intervals. number of studies focusing on risk factors of contralateral occult PTC. In this study, we used our retrospective research data and reviewed all related literature on the website that conducted this meta-analysis, aiming to estimate the risk factors for contralateral occult carcinoma in patients with unilateral PTC.

\section{MATERIALS AND METHODS}

We collected the clinical data of patients with PTC treated in the First Hospital of China Medical University (Shenyang, China) from January 2016 to January 2021. Data collected included age, sex, thyroid ultrasound report, operation record, diagnosis, and pathology report. The inclusion criteria were as follows: PTC confined to the only unilateral lobe by preoperative image examinations or fine-needle aspiration cytology; patients who underwent initially total or near-total thyroidectomy; and postoperative pathological examination confirming the unilateral lesion was PTC. Also, the exclusion criteria were as follows: the patients had a suspicious lesion on the contralateral lobe; PTC located in the isthmus. Finally, 204 patients were included in our study, in which 27 patients were with contralateral occult PTC (confirmed by pathological examination). These clinical data were included in the meta-analysis.

Our meta-analysis was conducted according to the guidelines proposed by the preferred reporting items for systematic review and meta-analyses statement (14).

\section{Search Strategy}

An electronic search of the PubMed, Embase, MEDLINE, Cochrane, and Web of Science databases was performed to identify relevant articles until December 7, 2020. We used the following search terms in "all fields": ((occult) AND (contralateral OR bilateral), AND (papillary thyroid) AND (carcinoma OR cancer OR tumor OR neoplasm)). Besides, a manual review of the references from the included studies was performed to identify additional relevant articles. Two authors independently performed the selection process, and the discrepancies were resolved by discussion. If multiple published studies illustrated the same population, we extracted the most complete or recent one.

\section{Selection Criteria}

We included studies that met the following criteria:

1. Prospective or retrospective original studies.

2. PTC confined to only the unilateral lobe by preoperative image examinations or FNA. 
3. Patients had initially undergone total or near-total thyroidectomy.

4. Pathologic examination confirming the presence of contralateral occult PTC.

5. Risk factors of contralateral occult PTC were available for extraction to calculate the pooled odds ratio (OR).

We excluded studies by the following criteria:

1. Reviews, case reports, letters to the editor, and conference abstracts.

2. Studies published in languages other than English and Chinese.

3. Studies enrolled patients with follicular thyroid carcinoma, medullary thyroid carcinoma, or anaplastic carcinoma.

4. The patients had a suspicious lesion on the contralateral lobe.

5. PTC located in the isthmus.

6. Lacked complete clinical data.

\section{DATA EXTRACTION AND QUALITY ASSESSMENT}

Each eligible study was extracted by two independent reviewers. Disagreements were resolved by consensus or adjudication of the senior authors. We extracted the following data from the included studies: (1) study characteristics: first author, publication year, country of study, study design, study population (PTC or PTMC), number of patients, and surgical extent; (2) clinicopathologic factors for contralateral occult carcinoma: sex, age, tumor size, ipsilateral multifocality, ETE, capsular invasion, BRAF mutation, Hashimoto thyroiditis (HT), presence of contralateral benign nodule, central lymph node metastasis (CLNM), and lateral lymph node metastasis (LLNM).

The included studies were estimated using the NewcastleOttawa scale (15), which allows evaluation of cohort studies by a total of eight items of three major parts, including the study population selection, comparability, and the result. A score of 0 to 9 stars was used to assess each study. A study achieving more than six stars was considered a high-quality study. All quality assessments were performed by two independent reviewers.

\section{STATISTICAL ANALYSIS}

The retrospective research data statistical analyses were performed using the SPSS v 26.0 software (Chicago, USA). The continuous variables are expressed as a mean \pm standard deviation (SD). Univariate analysis for comparisons between patient groups was performed using Pearson's chi-square test or Fisher's exact test. Variables with a $\mathrm{p}<0.05$ in the univariate analysis were included in the multivariable analysis. Logistic regression analysis was performed to assess the risk factors of contralateral occult carcinoma.

We performed the meta-analysis by Revman Manager 5.0 (Cochrane Collaboration, Oxford, UK). The OR was used to compare dichotomous variables. All results were estimated with 95\% confidence intervals (CIs). A P-value $<0.05$ was considered statistically significant. Heterogeneity was examined by using the Q-test and $\mathrm{I}^{2}$ statistic. When $\mathrm{p}>0.1$ and $\mathrm{I}^{2}<50 \%$, a fixed-effect model was used; otherwise, a random-effects model was applied. Possible publication bias was tested using Begg's funnel plot.

\section{RESULTS}

\section{Retrospective Study}

\section{Patients and Tumor Characteristics}

After screening the medical records, 204 patients met the criteria and were included in the study. Of these patients, $47(23.0 \%)$ were men, and 157 (77.0\%) were women. The average age was 42.5 years, and the age range was 22 to 67 years. Briefly, 172 (84.3\%) patients were younger than 55 years, and 32 (15.7\%) were 55 years and older. All patients underwent surgical treatment. The average tumor size was $1.28 \mathrm{~cm}$, and the size range was 0.32 to $5.80 \mathrm{~cm}$. In $93(45.6 \%)$ patients, the tumor size was $\leq 1 \mathrm{~cm}$; and in $111(54.4 \%)$ patients, the tumor size was > $1 \mathrm{~cm}$. For the patients included, 27 (13.2\%) had contralateral occult carcinoma and 177 (13.2\%) did not; 21 (10.3\%) patients had ETE and 183 (89.7\%) patients did not; 65 (31.9\%) patients had central lymph node metastasis, 40 (19.6\%) patients had lateral lymph node metastasis, and 99 (48.5\%) patients were without lymph node metastasis (Table 1).

\section{Clinicopathological Factors Associated With Contralateral Occult Carcinoma}

Among the 27 patients with occult lesions in the contralateral gland, $5(18.5 \%)$ were men and 22 (81.5\%) were women. Twentythree $(85.2 \%)$ patients were younger than 55 years and four (12.5\%) patients were 55 years and older. The mean tumor size of the contralateral occult lesion was $2.00 \pm 1.29$, and the noncontralateral occult lesion was $1.14 \pm 0.60$. Six $(22.2 \%)$ patients had a tumor size $\leq 1 \mathrm{~cm}$, and $21(77.7 \%)$ patients had a tumor size $>1 \mathrm{~cm}$. Contralateral occult carcinoma presented with a significant association with tumor size and the presence of ETE, CLNM, and LLNM by univariate analysis (all $p<0.05$ ). All of these factors were included in the multivariate analysis, which showed that a tumor size $>1 \mathrm{~cm}(\mathrm{OR}=3.461,95 \% \mathrm{CI}=1.333-$ $8.984, \mathrm{p}=0.011)$ and the presence of ETE $(\mathrm{OR}=11.481,95 \%$ $\mathrm{CI}=4.231-31.154, \mathrm{p}<0.001), \mathrm{CLNM}(\mathrm{OR}=2.086,95 \% \mathrm{CI}=$ $1.246-3.495, \mathrm{p}=0.005)$, and LLNM $(\mathrm{OR}=6.765,95 \% \mathrm{CI}=$ $1.877-24.380, \mathrm{p}=0.003)$ were independent predictors of contralateral occult carcinoma (Table 1).

\section{Meta-Analysis}

After searching the databases, 118 studies were initially found, and 77 articles were determined to be non-overlapping articles. Eleven articles were excluded because of language, seven studies were excluded because they were case reports, and 43 studies were excluded because the title or abstract was not applicable. The remaining 16 articles were subjected to a full-text evaluation. However, patients in the five studies were non-unilateral PTC 
TABLE 1 | Associations between clinicopathological characteristics and contralateral occult carcinoma in PTC patients.

\begin{tabular}{|c|c|c|c|c|c|c|c|}
\hline Variables & Overall $(\mathrm{N}=204)$ & $\begin{array}{l}\text { Contralateral occult } \\
\qquad N=27(13.2 \%)\end{array}$ & $\begin{array}{l}\text { Non-contralateral occult lesion } \\
\qquad N=177(86.8 \%)\end{array}$ & $P$ value & OR & $95 \% \mathrm{Cl}$ & P value \\
\hline \multicolumn{8}{|l|}{ Sex } \\
\hline Male & $47(23.0)$ & 5 (10.6) & $42(89.4)$ & 0.549 & & & \\
\hline Female & 157 (77.0) & $22(14.0)$ & 135 (86.0) & & & & \\
\hline Age $(Y)$ & $42.51 \pm 10.42$ & $42.85 \pm 9.12$ & $42.46 \pm 10.63$ & & & & \\
\hline$<55$ & 172 (84.3) & $23(13.4)$ & 149 (86.6) & 0.894 & & & \\
\hline$\geq 55$ & 32 (15.7) & $4(12.5)$ & 28 (87.5) & & & & \\
\hline Tumor size (cm) & $1.28 \pm 0.77$ & $2.00 \pm 1.29$ & $1.14 \pm 0.60$ & & & & \\
\hline$\leq 1$ & $94(46.1)$ & $6(6.4)$ & 88 (93.6) & 0.008 & 1 & & \\
\hline$>1$ & 110 (53.9) & $21(19.1)$ & $89(80.9)$ & & 3.461 & 1.333-8.984 & 0.011 \\
\hline \multicolumn{8}{|l|}{ ETE } \\
\hline Absence & $183(89.7)$ & $16(8.7)$ & $167(91.3)$ & $<0.001$ & 1 & & \\
\hline Presence & $21(10.3)$ & $11(52.4)$ & $10(47.6)$ & & 11.481 & $4.231-31.154$ & $<0.001$ \\
\hline \multicolumn{8}{|l|}{ LNM } \\
\hline Without LNM & 99 (48.5) & $5(5.1)$ & $94(94.9)$ & 0.004 & 1 & & \\
\hline CLNM & 65 (31.9) & $14(21.5)$ & $51(78.5)$ & & 2.086 & $1.246-3.495$ & 0.005 \\
\hline LLNM & 40 (19.6) & 8 (20.0) & $32(80.0)$ & & 6.765 & $1.877-24.380$ & 0.003 \\
\hline
\end{tabular}

PTC, papillary thyroid carcinoma; Y, year; ETE, extrathyroidal extension; LNM, lymph node metastasis; CLNM, central lymph node metastasis; LLNM, lateral Iymph node metastasis; OR, odds ratio; $95 \% \mathrm{Cl}$, 95\% confidence interval.

preoperatively, data could not be obtained in two studies, and one study had an overlapping population. A flowchart with details is displayed in Figure 1. Finally, a total of nine studies were included in the meta-analysis with our retrospective research data included. Table 2 shows the baseline characteristics and quality scores of the nine studies included, which consisted of two prospective and seven retrospective studies with a total of 4347 patients enrolled. Eight studies were conducted in China and one in South Korea. All the studies enrolled patients who underwent TT or NT for the treatment of PTC confined to the unilateral lobe, without suspicious carcinoma lesion in the contralateral lobe by preoperative image examinations or FNA. Contralateral occult PTC was defined as a tumor lesion detected by pathology postoperatively in the contralateral lobe rather than detected by preoperative examinations. The prevalence of contralateral occult PTC in each study was available and ranged from $11.95 \%$ to $46.9 \%$ (median $16.7 \%$ ). Among the 4,347 patients enrolled, contralateral occult PTC was reported in 1,150 patients, and the prevalence was $26.6 \%$. According to Newcastle-Ottawa Scale (NOS), three studies were rewarded 6 stars, and six studies were rewarded 7 stars. The average award of the nine studies was 6.7 stars on a scale of 0 to 9 . All studies were considered adequate for meta-analysis.

\section{Sex}

There were 204 patients who met the criteria and were included in this retrospective study. Of these patients, 47 (23.0\%) were men and $157(77.0 \%)$ were women. There were $27(13.2 \%)$ patients who had contralateral occult carcinoma and 177 (13.2\%) did not; among the 27 patients with contralateral occult PTC, 5 (18.5\%) were men, and 22 (81.5\%) were women, sex had nothing to do with whether patients had contralateral occult PTC (Table 1).

Nine studies reported the relationship between the risk of contralateral occult PTC and sex, including our retrospective study. The pooled analysis revealed that sex was not associated with contralateral occult PTC (pooled OR $=0.98,95 \%$ CI $-0.83-$ $1.16, \mathrm{p}=0.80)$ (Figure 2A).

\section{Age}

Age is a critical factor in outcomes for patients with welldifferentiated thyroid cancer. Forty-five years was used as the cutoff value in staging before 2016. In four studies, the cutoff value for age was 45 years, and the pooled analysis revealed that 45 years as a cutoff value for age was not associated with the contralateral occult PTC (pooled OR $=0.93,95 \% \mathrm{CI}=0.69-1.25$, $\mathrm{p}=0.33$ ) (Figure 2B).

However, there is increasing evidence to suggest that regarded 45 years as the cutoff value for age may be too low. The newest guideline in the AJCC/UICC staging system changed the cutoff value for age from 45 years to 55 years in 2017. In our retrospective study, the patients' average age was 42.5 years, and the age range was 22 to 67 years. Briefly, $172(84.3 \%)$ patients were younger than 55 years, and $32(15.7 \%)$ patients were 55 years and older. In the 27 patients who had occult lesions in the contralateral gland, 23 patients $(85.2 \%)$ were younger than 55 years, and 4 patients (12.5\%) were 55 years or older. There were no differences on whether which patients had contralateral occult PTC between the two groups younger than 55 years and 55 years or older (Table 1). The results of the meta-analysis showed that the age cutoff value of 55 years was not associated with the contralateral occult PTC (pooled OR $=1.53,95 \% \mathrm{CI}=0.87-2.68$, $\mathrm{p}=0.50)$ (Figure 2C).

\section{Tumor Size}

In our retrospective study of 204 included PTC patients, the average tumor size was $1.28 \mathrm{~cm}$, and the size range was 0.32 to $5.80 \mathrm{~cm}$. In $93(45.6 \%)$ patients, the tumor size was $\leq 1 \mathrm{~cm}$, and for the other $111(54.4 \%)$ patients, the tumor size was $>1 \mathrm{~cm}$. However, in the contralateral occult PTC group, the mean tumor size of the lesion was $2.00 \pm 1.29$; and in the non-contralateral occult group, this value was $1.14 \pm 0.60$. In the contralateral occult PTC group, there were 6 (22.2\%) patients whose tumor 


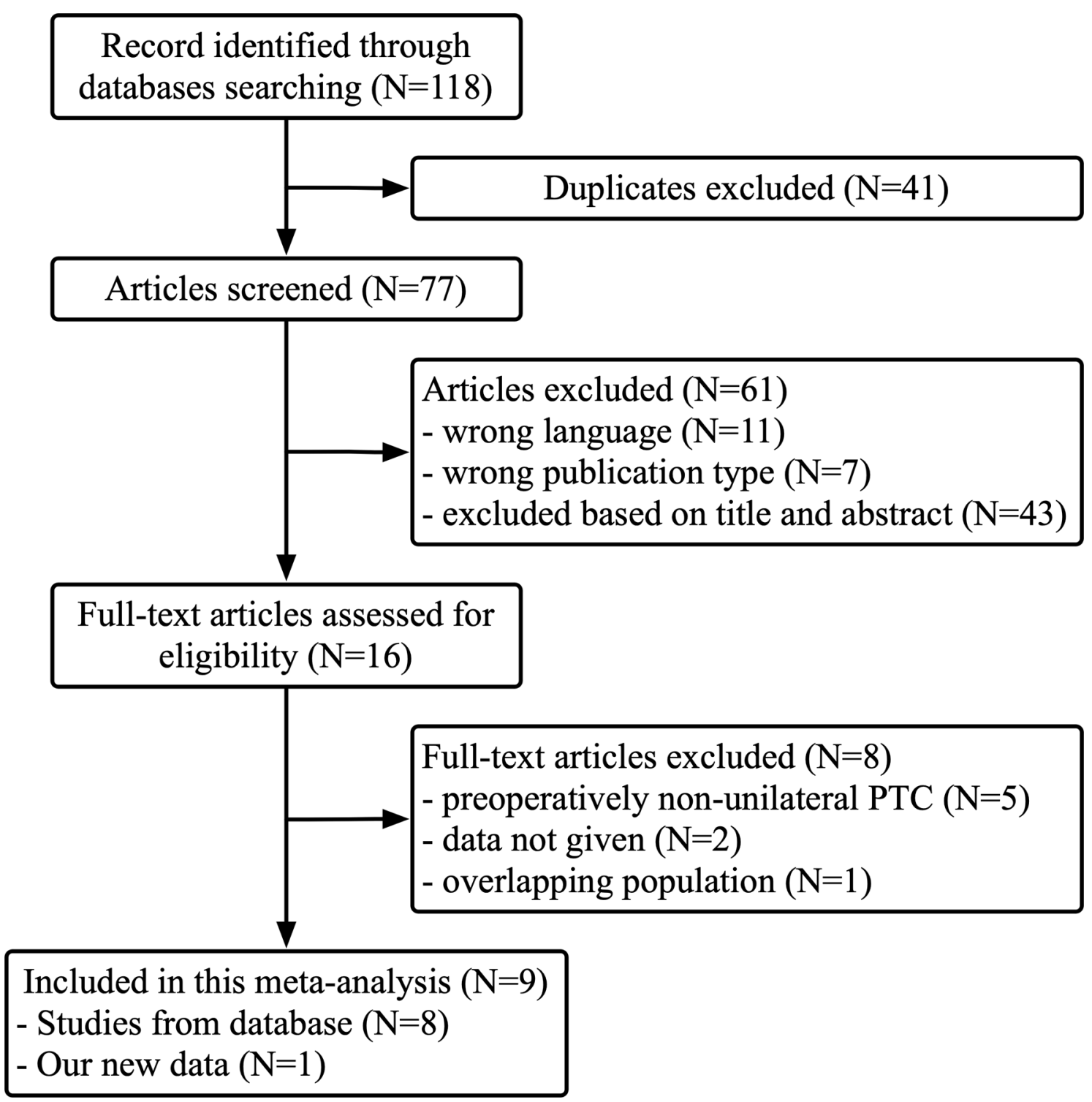

FIGURE 1 | Flow chart of the study selection process.

size was $\leq 1 \mathrm{~cm}$, and $21(77.7 \%)$ patients whose tumor size was > $1 \mathrm{~cm}$. The results of the univariate analysis showed that the presence of contralateral occult PTC had a significant association with tumor size $(\mathrm{p}<0.05)$. Also, the multivariable analysis showed that tumor size $>1 \mathrm{~cm}(\mathrm{OR}=3.461,95 \% \mathrm{CI}=1.333-8.984, \mathrm{p}=$ 0.011 ) was an independent predictor of contralateral occult PTC (Table 1).

There were four studies (included our study) that estimated the effect of tumor size on contralateral occult PTC using the cutoff value of $1.0 \mathrm{~cm}$. Findings from the pooled analysis suggested that the risk of contralateral occult PTC was significantly higher in patients with a tumor size $>1 \mathrm{~cm}$ than patients with a tumor size $\leq 1 \mathrm{~cm}$ (pooled $\mathrm{OR}=2.16,95 \% \mathrm{CI}=$ 1.29-3.61, $\mathrm{p}=0.003$ ) (Figure 2D).

\section{Ipsilateral Multifocality}

There were six studies that addressed the association between the risk of contralateral occult PTC and ipsilateral multifocality. Because of the low heterogeneity among the studies $\left(\mathrm{I}^{2}=45 \%\right.$, $\mathrm{p}=0.11$ ), a fixed-effects model was used to analyze the data. Compared with patients without ipsilateral multifocality, patients with ipsilateral multifocality had a higher prevalence of contralateral occult PTC (pooled OR $=5.62,95 \% \mathrm{CI}=4.53-$ 6.99, $\mathrm{p}<0.00001$ ) (Figure 2E).

\section{Extrathyroidal Extension (ETE)}

In the 204 PTC patients included in this retrospective study, 21 (10.3\%) patients had ETE and 183 patients (89.7\%) did not. However, in the contralateral occult PTC group, there were 11 
TABLE 2 | Characteristics of the nine included studies.

\begin{tabular}{|c|c|c|c|c|c|c|c|c|c|}
\hline Author & Year & Country & Study Period & $\begin{array}{l}\text { Study } \\
\text { Design }\end{array}$ & $\begin{array}{c}\text { Study } \\
\text { Population }\end{array}$ & Case & Surgical Extent & $\begin{array}{c}\text { Prevalence of contralateral } \\
\text { occult PTC (\%) }\end{array}$ & $\begin{array}{c}\text { Quality } \\
\text { assessment }\end{array}$ \\
\hline Chen XH (12) & 2020 & China & 2014/1-2017/9 & Retrospective & PTC & 921 & TT/NT+CLND/CLND+LLND & 16.7 & 6 \\
\hline Feng JW (16) & 2020 & China & 2011/1-2018/1 & Retrospective & PTC & 552 & $\Pi T+C L N D / C L N D+L L N D$ & 16.1 & 7 \\
\hline Gu JL (17) & 2020 & China & 2012/9-2014/9 & Retrospective & PTC & 300 & TT+CLND/CLND+LLND & 18.3 & 7 \\
\hline Koo BS (18) & 2010 & Korea & 2005/3-2009/3 & Retrospective & PTMC & 132 & $T+C L N D$ & 16.7 & 7 \\
\hline Lv T (19) & 2018 & China & 2014/1-2016/12 & Retrospective & PTC & 1442 & $\pi+C L N D$ & 46.9 & 7 \\
\hline Wan HF (13) & 2015 & China & 2011/1-2013/12 & Prospective & PTMC & 89 & $\Pi+$ selective LND & 40.4 & 7 \\
\hline Wang N (11) & 2020 & China & 2016/5-2018/6 & Retrospective & PTC & 586 & $\Pi+$ cervical LND & 11.95 & 6 \\
\hline Zhou YL (20) & 2012 & China & 2010/11-2011/11 & Prospective & PTMC & 100 & $T+C L N D$ & 20 & 6 \\
\hline Our new data & 2021 & China & 2016/1-2021/1 & Retrospective & PTC & 204 & $\pi+C L N D / C L N D+L L N D$ & 13.2 & 7 \\
\hline
\end{tabular}

PTC, papillary thyroid carcinoma; PTMC, papillary thyroid microcarcinoma; TT, total thyroidectomy; NT, near-total thyroidectomy; CLND, central Iymph node dissection; LLND, lateral lymph node dissection; LND, lymph node dissection.

(40.7\%) patients with ETE, the other 16 patients (59.3) did not. The results of the univariate analysis showed that the presence of contralateral occult PTC had a significant association with ETE $(\mathrm{p}<0.05)$. Also, the multivariable analysis showed that the presence of ETE $(\mathrm{OR}=11.481,95 \% \mathrm{CI}=4.231(40.7 \%) 31.154, \mathrm{p}<0.001)$ was an independent predictor of contralateral occult PTC (Table 1).

Seven studies analyzed the impact of ETE on contralateral occult PTC (including our new data). This pooled analysis suggested no significant association between ETE and contralateral occult PTC (pooled OR $=1.99,95 \%$ CI $=0.63-$ 6.26, $\mathrm{p}=0.24)$ (Figure 3A).

\section{Capsular Invasion}

Five studies addressed the association between the risk of contralateral occult PTC and capsular invasion. This risk factor showed low heterogeneity among the studies $\left(\mathrm{I}^{2}=30 \%, \mathrm{p}=0.22\right)$. Results from the meta-analyses exhibited that the risk of capsular invasion was not associated with contralateral occult PTC (pooled OR $=1.20,95 \% \mathrm{CI}=0.94-1.54, \mathrm{p}=0.15)($ Figure 3B $)$.

\section{BRAF Mutation}

Six studies analyzed the impact of a BRAF mutation on contralateral occult PTC. The heterogeneity was 52\% ( $\mathrm{p}=$ 0.07). This pooled analysis suggested no significant association between a BRAF mutation and contralateral occult PTC (pooled $\mathrm{OR}=1.58,95 \% \mathrm{CI}=0.98-2.56, \mathrm{p}=0.06)$ (Figure 3C).

\section{Hashimoto Thyroiditis (HT)}

An association between the risk of contralateral occult PTC and HT was investigated in four studies. Because no statistically significant heterogeneity was detected between the studies $\left(\mathrm{I}^{2}=\right.$ $0 \%, p=0.67$ ), a fixed-effects model was applied to assess the data. The results from the meta-analyses showed that the risk of HT was not associated with contralateral occult PTC (pooled OR = $0.89,95 \% \mathrm{CI}=0.61-1.30, \mathrm{p}=0.54)$ (Figure 3D).

\section{Contralateral Benign Nodule}

Three studies estimated the effect of a contralateral benign nodule on contralateral occult PTC. Findings from the pooled analysis suggested that compared to patients without a contralateral benign nodule, patients with a contralateral benign nodule had a higher prevalence of contralateral occult PTC $($ pooled OR $=2.45,95 \% \mathrm{CI}=$ 1.20-5.03, $\mathrm{p}=0.01$ ) (Figure 3E).

\section{Lymph Node Metastasis}

In our new data results, there were $65(31.9 \%)$ patients who had central lymph node metastasis, $40(19.6 \%)$ patients had lateral lymph node metastasis, and 99 (48.5\%) patients without lymph node metastasis. However, in the contralateral occult PTC group, there were 14 (51.9\%) patients with CLNM, 8 (29.6) patients with LLNM, and 5 (18.5\%) patients without LNM. The results of the univariate analysis showed that the presence of contralateral occult PTC had a significant association with LNM $(\mathrm{p}<0.05)$. Also, the multivariable analysis showed that the presence of CLNM (OR $=2.086,95 \% \mathrm{CI}=1.246-3.495, \mathrm{p}=0.005)$ and LLNM $(\mathrm{OR}=6.765,95 \% \mathrm{CI}=1.877-24.380, \mathrm{p}=0.003)$ were independent predictors of contralateral occult PTC (Table 1).

An association between the risk of contralateral occult PTC and CLNM was investigated in six studies. The heterogeneity was high ( $\mathrm{I} 2=88 \%, \mathrm{p}<0.00001)$, and the results from the metaanalyses showed that the risk of contralateral occult PTC was significantly higher in patients with CLNM than patients without CLNM (pooled OR $=2.80,95 \% \mathrm{CI}=1.35-5.81, \mathrm{p}=$ 0.006) (Figure 4A).

There were three studies that analyzed the impact of LLNM on contralateral occult PTC. The analysis suggested no significant association between LLNM and contralateral occult PTC (pooled OR $=3.99,95 \% \mathrm{CI}=0.81-19.67, \mathrm{p}=0.09$ ) (Figure 4B).

\section{DISCUSSION}

Thyroid cancer has been the most rapidly increasing cancer over the past few decades in many countries. PTC comprises $90 \%$ of all thyroid malignancies and has an excellent prognosis with conventional therapies, such as surgery and radioactive iodine therapy. According to the latest ATA guidelines, TT is recommended for patients with a tumor $>4 \mathrm{~cm}$, gross maximal ETE (T4), cervical lymph node metastasis, or distant metastasis. In addition, TL is endorsed as an initial surgical approach for low-risk, small- to medium-sized (T1-T2), N0 PTC in the absence of ETE (10). Considering that TT is associated with an increased risk of complications, such as vocal cord palsy and hypoparathyroidism $(3,21)$, TL may be sufficient for unilateral PTC with tumors $<4 \mathrm{~cm}$ and without ETE or clinical evidence of lymph node metastasis. There is no disagreement to performing $\mathrm{TT}$ for tumors detected 
A

\begin{tabular}{|c|c|c|c|c|c|c|c|c|c|}
\hline Study or Subgroup & $\begin{array}{r}\text { mal } \\
\text { Events }\end{array}$ & Total & $\begin{array}{r}\text { fema } \\
\text { Events }\end{array}$ & $\begin{array}{l}\text { le } \\
\text { Total }\end{array}$ & Weight & $\begin{array}{c}\text { Odds Ratio } \\
\text { M-H, Fixed, } 95 \% \mathrm{Cl}\end{array}$ & & $\begin{array}{c}\text { Odds Ratio } \\
\text { M-H, Fixed, } 95 \% \mathrm{CI}\end{array}$ & \\
\hline Chen XH 2020 & 42 & 278 & 112 & 643 & $20.9 \%$ & $0.84[0.57,1.24]$ & & $\longrightarrow+$ & \\
\hline Feng JW 2020 & 67 & 435 & 22 & 117 & $10.7 \%$ & $0.79[0.46,1.34]$ & & - & \\
\hline Gu JL 2016 & 16 & 62 & 39 & 238 & $4.4 \%$ & $1.77[0.91,3.45]$ & & & \\
\hline Koo BS 2010 & 3 & 12 & 19 & 120 & $0.9 \%$ & $1.77[0.44,7.15]$ & & & \\
\hline Lv T 2018 & 164 & 345 & 513 & 1097 & $47.0 \%$ & $1.03[0.81,1.31]$ & & - & \\
\hline Our New Data 2021 & 5 & 47 & 22 & 157 & $3.3 \%$ & $0.73[0.26,2.05]$ & & & \\
\hline Wan HF 2015 & 8 & 20 & 28 & 69 & $2.8 \%$ & $0.98[0.35,2.69]$ & & & \\
\hline Wang N 2020 & 14 & 133 & 56 & 453 & $8.3 \%$ & $0.83[0.45,1.55]$ & & & \\
\hline Zhou YL 2012 & 4 & 19 & 16 & 81 & $1.8 \%$ & $1.08[0.32,3.71]$ & & & \\
\hline Total $(95 \% \mathrm{Cl})$ & & 1351 & & 2975 & $100.0 \%$ & $0.98[0.83,1.16]$ & & & \\
\hline Total events & 323 & & 827 & & & & & & \\
\hline $\begin{array}{l}\text { Heterogeneity: } \mathrm{Chi}^{2}= \\
\text { Test for overall effect }\end{array}$ & $\begin{array}{l}5.77, d f \\
Z=0.25\end{array}$ & $\begin{array}{l}=8(P \\
(P=0\end{array}$ & $\begin{array}{l}=0.67) \text {; } \\
.80)\end{array}$ & $I^{2}=0 \%$ & & & $\begin{array}{ll}0.1 & 1 \\
0.2\end{array}$ & $0.5{ }_{\text {male }}^{1}{ }^{1}{ }^{1}{ }^{2}$ & $\overrightarrow{10}$ \\
\hline
\end{tabular}

B

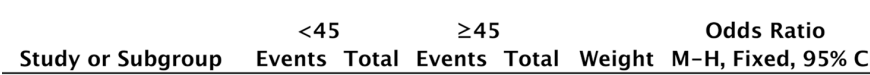

$\begin{array}{llrrrrr}\text { Chen XH } 2020 & 86 & 550 & 68 & 371 & 74.7 \% & 0.83[0.58,1.17]\end{array}$

Koo BS 2010

Wan HF 2015

Zhou YL 2012

$\begin{array}{rrrrr}8 & 49 & 14 & 83 & 9.5 \%\end{array}$

$0.83[0.58,1.17]$
$0.96[0.37,2.49]$

$2.03[0.83,4.95]$

Total $(95 \% \mathrm{Cl})$

$\begin{array}{rr}25 & 53 \\ 6 & 33\end{array}$

$11 \quad 36$

$0.84[0.29,2.43]$

Total events

685

$\begin{array}{lcc}\text { Total events } & 125 & 107 \\ \text { Heterogeneity: } \mathrm{Chi}^{2}=3.43, \mathrm{df}=3(\mathrm{P}=0.33) ; \mathrm{I}^{2}=13 \%\end{array}$

$557 \quad 100.0 \%$

$0.93[0.69,1.25]$

Test for overall effect: $Z=0.48(P=0.63)$

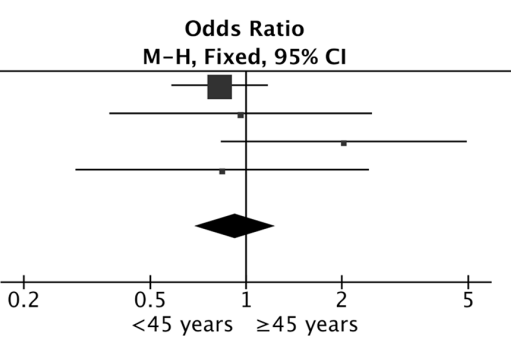

C

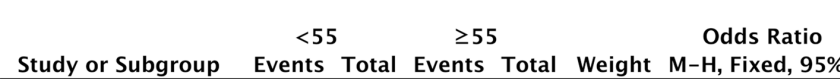

\begin{tabular}{lrrrrrr} 
& \\
\hline Feng JW 2020 & 77 & 460 & 12 & 113 & $73.3 \%$ & $1.69[0.89,3.23]$
\end{tabular}

$\begin{array}{lllrrrr}\text { Our New Data } 2021 & 23 & 172 & 4 & 32 & 26.7 \% & 1.08[0.35,3.36]\end{array}$

Total $(95 \% \mathrm{Cl})$

Total events

632

100

$145 \quad 100.0 \%$

$1.53[0.87,2.68]$

Heterogeneity: $\mathrm{Chi}^{2}=0.45, \mathrm{df}=1(\mathrm{P}=0.50) ; \mathrm{I}^{2}=0 \%$

Test for overall effect: $Z=1.48(P=0.14)$

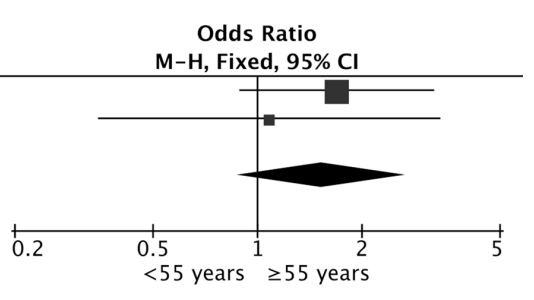

D

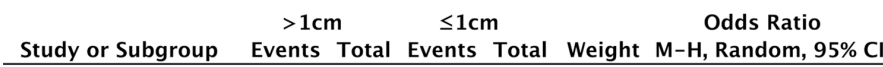

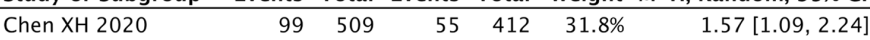
$\begin{array}{lllllll}\text { Feng JW } 2020 & 67 & 277 & 22 & 275 & 27.3 \% & 3.67[2.19,6.14]\end{array}$ $\begin{array}{lrrrrrr}\text { Gu JL 2016 } & 20 & 93 & 35 & 207 & 24.5 \% & 1.35[0.73,2.49]\end{array}$ Our New Data 2021

$\begin{array}{lrrrr}21 & 111 & 6 & 93 & 16.4 \%\end{array}$

$3.38[1.30,8.78]$

Total $(95 \% \mathrm{Cl})$

990

Total events

207

$987 \quad 100.0 \%$

$2.16[1.29,3.61]$

Heterogeneity: $\mathrm{Tau}^{2}=0.18 ; \mathrm{Chi}^{2}=9.89, \mathrm{df}=3(\mathrm{P}=0.02) ; \mathrm{I}^{2}=70 \%$

Test for overall effect: $Z=2.94(P=0.003)$

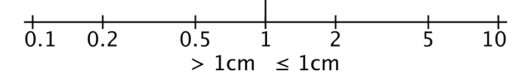

$\mathbf{E}$

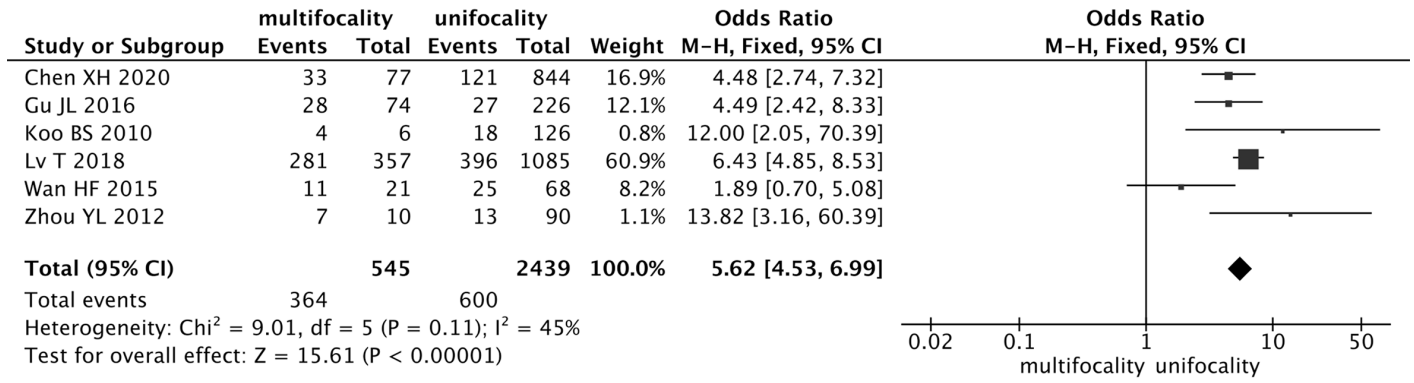

FIGURE 2 | Forest plots of the association between contralateral occult PTC (papillary thyroid carcinoma) and all risk factors: (A) Sex was not associated with contralateral occult PTC (pooled OR $=0.98,95 \% \mathrm{Cl}=0.83-1.16, \mathrm{p}=0.80$ ); (B) The risk of age (cut-off value was 55) was not associated with contralateral occult PTC (pooled OR $=1.53,95 \% \mathrm{Cl}=0.87-2.68, \mathrm{p}=0.14$ ); (C) The risk of age (cut-off value was 45) was not associated with contralateral occult PTC (pooled OR = $0.93,95 \% \mathrm{Cl}=0.69-1.25, \mathrm{p}=0.63)$; (D) The risk of contralateral occult PTC was significantly higher in patients with a tumor $>1 \mathrm{~cm}$ than patients with a tumor $\leq$ $1 \mathrm{~cm}$ (pooled $\mathrm{OR}=2.16,95 \% \mathrm{Cl}=1.1 .29-3.61, \mathrm{p}=0.003$ ); $(\mathrm{E})$ Compared with patients without ipsilateral multifocality, patients with ipsilateral multifocality had a higher prevalence of contralateral occult PTC (pooled OR $=5.62,95 \% \mathrm{Cl}=4.53-6.99, \mathrm{p}<0.00001$ ). 
A

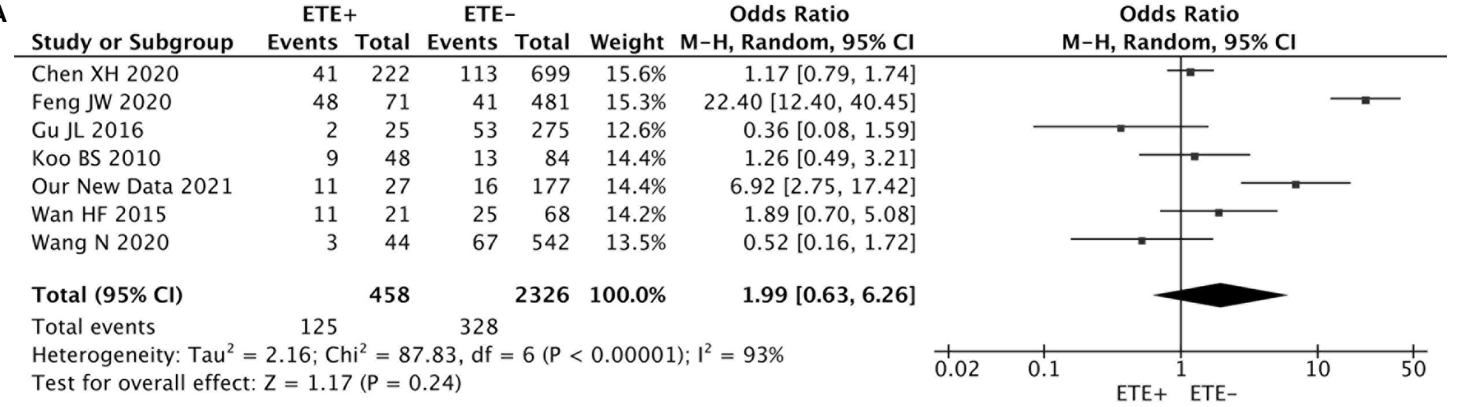

B

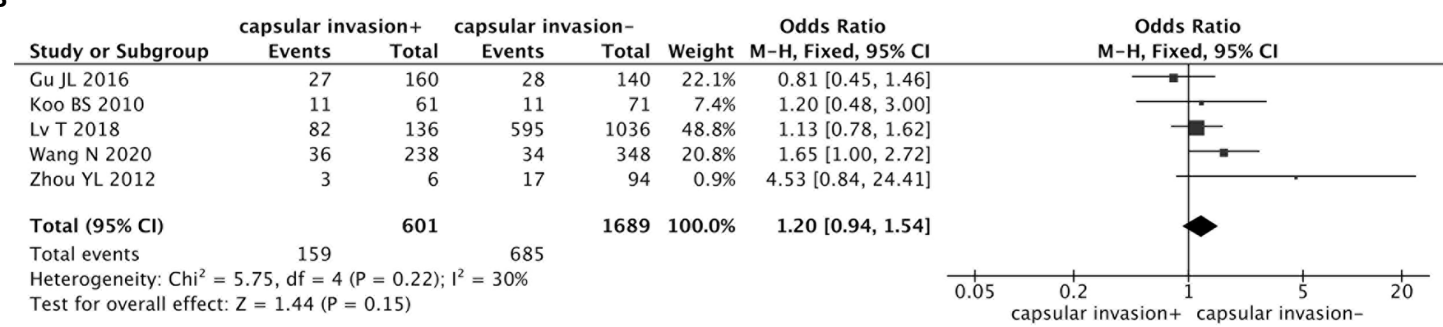

C

BRAF+ BRAF-

Odds Ratio

Study or Subgroup Events Total Events Total Weight $\mathrm{M}-\mathrm{H}, \mathrm{Random}, 95 \% \mathrm{CI}$

$\begin{array}{lllllll}\text { Chen XH } 2020 & 62 & 328 & 92 & 593 & 30.1 \% & 1.27[0.89,1.81]\end{array}$

Feng JW 2020

Lv T 2018

Wan HF 2015

Wang N 2020

Zhou YL 2012

Total $(95 \% \mathrm{Cl})$

$13 \quad 54$

$\begin{array}{lllll}13 & 54 & 1 & 7 & 4.2 \%\end{array}$

$1.90[0.21,17.29]$

$2.51[1.18,5.32]$

$0.77[0.33,1.82]$

$1.09[0.45,2.66]$

$4.82[1.72,13.52]$

$\begin{array}{lcc}\text { Total events } & 211 & 156 \\ \text { Heterogeneity: } \mathrm{Tau}^{2}=0.17 ; \mathrm{Chi}^{2}=10.31, \mathrm{df}=5(\mathrm{P}=0.07) & \mathrm{I}^{2}=52 \%\end{array}$

$\begin{array}{rrrrr}64 & 532 & 22 & 51 & 16.7 \% \\ 12 & 31 & 6 & 54 & 16.2 \%\end{array}$

Test for overall effect: $Z=1.87(P=0.06)$

$1.58[0.98,2.56]$

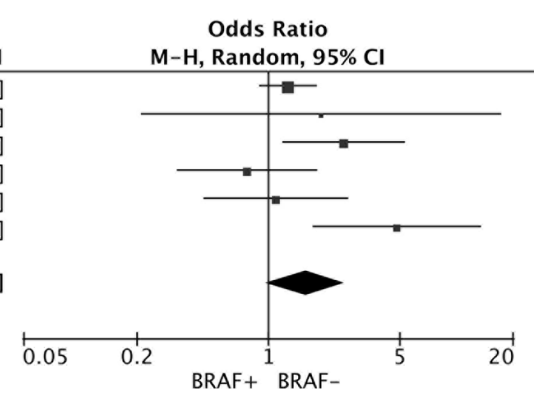

D

Study or Subgroup Events Total Events Total Weight $\mathrm{M}-\mathrm{H}$, Fixed, $95 \% \mathrm{Cl}$

Gu JL 2016

$\begin{array}{lrrrr}7 & 50 & 48 & 250 & 24.1 \%\end{array}$

$0.69[0.29,1.62]$

Wan HF 2015

Wang N 2020

Zhou YL 2012

$\begin{array}{llrrr}7 & 18 & 29 & 71 & 12.5 \%\end{array}$

$\begin{array}{ll}7 & 18\end{array}$

$71 \quad 12.5 \%$

$0.92[0.32,2.66]$

$0.85[0.50,1.42]$

Total $(95 \% \mathrm{Cl})$

$8 \quad 32$

$\begin{array}{rrr}26 & 198 & 53.4 \%\end{array}$

$1.56[0.56,4.29]$

Total events

488

$587 \quad 100.0 \%$

$0.89[0.61,1.30]$

Heterogeneity: $\mathrm{Chi}^{2}=1.56, \mathrm{df}=3(\mathrm{P}=0.67) ; \mathrm{I}^{2}=0 \%$

Test for overall effect: $Z=0.61(P=0.54)$

\begin{tabular}{|c|c|c|c|c|c|c|c|c|c|c|}
\hline Study or Subgroup & contralateral nodule+ & $\begin{array}{l}\text { Iule+ } \\
\text { Total }\end{array}$ & \multicolumn{2}{|c|}{ contralateral nodule- } & Weight & $\begin{array}{c}\text { Odds Ratio } \\
\text { M-H, Random, } 95 \% \mathrm{CI}\end{array}$ & \multicolumn{3}{|c|}{$\begin{array}{c}\text { Odds Ratio } \\
\mathrm{M}-\mathrm{H}, \text { Random, } 95 \% \mathrm{Cl}\end{array}$} & \\
\hline Chen XH 2020 & 93 & 347 & 61 & 574 & $48.6 \%$ & $3.08[2.16,4.40]$ & & & -2- & \\
\hline Gu JL 2016 & 49 & 266 & 6 & 34 & $28.5 \%$ & $1.05[0.41,2.68]$ & & & & \\
\hline Koo BS 2010 & 18 & 74 & 4 & 58 & $22.9 \%$ & $4.34[1.38,13.65]$ & & & & \\
\hline Total $(95 \% \mathrm{Cl})$ & & 687 & & 666 & $100.0 \%$ & $2.45[1.20,5.03]$ & & & & \\
\hline Total events & 160 & & 71 & & & & & & & \\
\hline $\begin{array}{l}\text { Heterogeneity: } \mathrm{Tau}^{2}= \\
\text { Test for overall effect }\end{array}$ & $\begin{array}{l}=0.24 ; \mathrm{Chi}^{2}=5 \\
: \mathrm{Z}=2.45(\mathrm{P}=\end{array}$ & $\mathrm{df}=2($ & $(P=0.08) ; I^{2}$ & & & & $\begin{array}{lc}0.1 & 0.2 \\
& \text { contralat }\end{array}$ & $\begin{array}{ll}0.5 \\
\text { nodule+ }\end{array}$ & 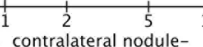 & 10 \\
\hline
\end{tabular}

FIGURE 3 | Forest plots of the association between contralateral occult PTC and all factors: (A) There was no significant association between ETE and contralateral occult PTC (pooled OR = 1.99, 95\% Cl =0.63-6.26, $\mathrm{p}=0.24$ ); (B) The risk of capsular invasion was not associated with contralateral occult PTC (pooled OR = $1.20,95 \% \mathrm{Cl}=0.94-1.54, \mathrm{p}=0.15)$; (C) There was no significant association between a BRAF mutation and contralateral occult PTC (pooled OR = 1.58, 95\% Cl = 0.98-2.56, $p=0.06$ ); (D) The risk of HT was not associated with contralateral occult PTC (pooled OR = 0.89, 95\% Cl=0.61-1.30, $p=0.54$ ); (E) Compared with patients without a contralateral benign nodule, patients with a contralateral benign nodule had a higher prevalence of contralateral occult PTC (pooled OR $=2.45$, $95 \% \mathrm{Cl}=1.20-5.03, \mathrm{p}=0.01)$. 
A

\begin{tabular}{|c|c|c|c|c|c|c|c|c|c|c|}
\hline Study or Subgroup & $\begin{array}{l}\text { CLNM } \\
\text { Events }\end{array}$ & $\begin{array}{l}\text { I+ } \\
\text { Total } \\
\end{array}$ & $\begin{array}{l}\text { CLNM } \\
\text { Events }\end{array}$ & Total & Weight & $\begin{array}{c}\text { Odds Ratio } \\
\mathrm{M}-\mathrm{H} \text {, Random, } 95 \% \mathrm{Cl}\end{array}$ & \multicolumn{4}{|c|}{$\begin{array}{l}\text { Odds Ratio } \\
\mathrm{M}-\mathrm{H} \text {, Random, } 95 \% \mathrm{Cl}\end{array}$} \\
\hline Feng JW 2020 & 74 & 260 & 15 & 392 & $18.2 \%$ & $10.00[5.59,17.90]$ & & & & $\longrightarrow$ \\
\hline Gu JL 2016 & 24 & 108 & 31 & 192 & $18.1 \%$ & $1.48[0.82,2.69]$ & & & & \\
\hline Koo BS 2010 & 7 & 25 & 15 & 107 & $14.6 \%$ & $2.39[0.85,6.68]$ & & & & \\
\hline LV T 2018 & 411 & 804 & 266 & 638 & $20.2 \%$ & $1.46[1.19,1.80]$ & & & - & \\
\hline Our New Data 2021 & 14 & 65 & 5 & 99 & $14.2 \%$ & $5.16[1.76,15.14]$ & & & & \\
\hline Zhou YL 2012 & 12 & 46 & 8 & 54 & $14.8 \%$ & $2.03[0.75,5.51]$ & & & & \\
\hline Total $(95 \% \mathrm{Cl})$ & & 1308 & & 1482 & $100.0 \%$ & $2.80[1.35,5.81]$ & & & & \\
\hline Total events & 542 & & 340 & & & & & & & \\
\hline $\begin{array}{l}\text { Heterogeneity: } \mathrm{Tau}^{2} \\
\text { Test for overall effec }\end{array}$ & $\begin{array}{l}0.67 ; \mathrm{Ch} \\
\mathrm{Z}=2.77\end{array}$ & $\begin{array}{l}i^{2}=41 \\
(P=0\end{array}$ & $\begin{array}{l}.72, \mathrm{df}= \\
.006)\end{array}$ & $=5(P<$ & 0.00001 & $1) ; 1^{2}=88 \%$ & 0.05 & 0.2 & & $\frac{1}{20}$ \\
\hline
\end{tabular}

B

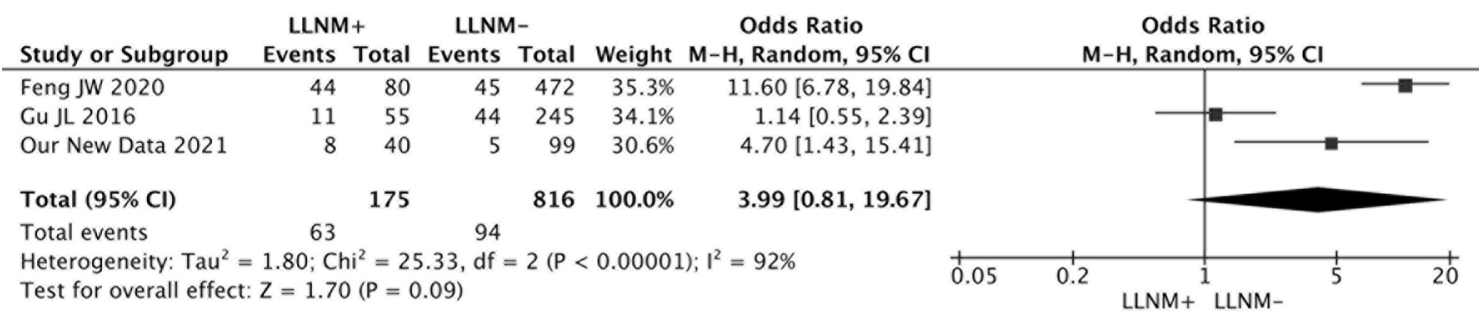

FIGURE 4 | (A) The risk of contralateral occult PTC was significantly higher in patients with CLNM than patients without CLNM (pooled OR $=2.80,95 \%$ Cl $=1.35-$ 5.81, $p=0.006$ ); (B) There was no significant association between LLNM and contralateral occult PTC (pooled OR $=3.99,95 \% \mathrm{Cl}=0.81-19.67, p=0.09$ ).

preoperatively in bilateral lobes. However, when unilateral lobectomy is performed for patients with contralateral occult PTC, occult foci would lead to local recurrence and cervical lymph node metastasis and even re-operation, which is related to higher surgical risks compared with primary surgery $(22,23)$. Hence, we attempted to identify the risk factors for contralateral occult carcinoma to help select high-risk patients with occult carcinoma who would benefit from more extensive treatment.

Among patients with PTC, male patients have higher rates of ETE, regional lymph node, and distant metastasis, and mortality than female patients, regardless of age (24). Liu et al. reported that the male gender is an independent poor prognostic factor for all PTCs, and more aggressive treatment options should be considered for men (25). However, our pooled data showed that sex is not associated with the occurrence of contralateral occult PTC. Thus, there is no need to consider expanding the scope of lymph node dissection due to sex differences.

The biology of PTC is highly dependent on age, with young patients outperforming older patients in terms of survival (26). The previous guideline for thyroid cancer used 45 years as the cutoff age, and 55 years was the cutoff age used since 2017 (27). Thus, inclusion of a few of the literatures that used the previous guideline standard was inevitable. We set up two forest figures to suit two different cutoff values. Considering the effect of age on PTC's biological activity, older patients whose PTC might more malignant, contralateral occult PTC might more likely to happen. However, the results of meta-analysis showed that regardless of whether the age cutoff value is 45 or 55 years, it did not affect the occurrence of the contralateral occult PTC. However, there were only two studies (included in our new data) that regarded 55 years as the cutoff age, and the OR value was higher than the 45 years cutoff age. Therefore, after expanding the sample size, this difference may become more significant.

Tumor size is the first factor evaluated for the biological characteristics of PTC because it is easily measured by preoperative US. The relationship between the size of the tumor and the presence of contralateral occult carcinoma remains controversial. It was concluded that tumor size is an independent predictor of bilaterality in PTC patients $(28,29)$. This is consistent with our new results. However, Pitt et al. examined a cohort of 228 patients and reported a rate of contralateral PTC for patients with primary tumors $\geq 1,<1$, and $<0.5 \mathrm{~cm}(30 \%, 26 \%$, and $27 \%$, respectively; nonsignificant p-value for all) (30). Combining the results of our meta-analysis, we suspected that Pitt's results are limited by sample size. We suggest that researchers should perform a larger cohort study to clarify this problem.

Multifocality is a unique feature of PTC, and the rate of multifocality is reported to be $20 \%$ to $30 \%(31,32)$. It was reported that increased tumor number is associated with higher rates of capsular invasion, ETE, and lymph node metastasis (33). A recent meta-analysis showed that multifocality in thyroid cancer increases the risk of disease recurrence (hazard ratio = 2.81; 95\% CI $=1.07-7.36$; $\mathrm{p}<0.001$ ) (34). What is more, Yoon et al. identified that multifocal tumors in the unilateral lobe have a high risk of bilateral carcinoma (9). Therefore, aggressive treatment, such as total thyroidectomy, central neck dissection, or postoperative radioactive iodine ablation, is suggested as the adequate treatment for multifocal PTCs. Our meta-analysis showed that patients with ipsilateral multifocal tumors have a 5.6-fold more contralateral occult PTC than patients with 
single-tumor foci. Thus, we strongly recommend patients with multifocality to pay attention to the presence of contralateral occult PTC.

An ETE is defined as an extension of the primary tumor beyond the thyroid capsule into the perithyroidal soft tissues, strap muscles, and adjacent structures (35). ETE is a well-known and significant factor for poor prognosis. It was reported that patients with ETE have a lower 10-year survival rate (75.2\%) and a lower 10-year disease-specific survival rate (84.2\%) (36). Also, Feng et al. reported that ETE is more commonly found in bilateral PTC than unilateral PTC $(20.2 \%$ vs. $11.4 \%, \mathrm{p}=0.016)$ (37). Therefore, it is conjectured that ETE would be a risk factor for contralateral concealed PTC, and our retrospective research also got the same results. However, this was not the case. The meta-analysis results showed that there was no association between ETE and contralateral occult PTC. We considered that the reason is that the ETE $(+)$ patients' number was insufficient, ETE (+) patients accounted for about $7 \%$ to $37 \%$ of the total number in every study. This led to greater heterogeneity. What is more, the two studies with $\mathrm{OR}$ value $<1$ (from $\mathrm{Gu}$ et al. and Wang et al. respectively) had a percentage $<10 \%$. Less ETE $(+)$ patients included, greater heterogeneity was important factor for the effect of ETE to contralateral occult PTC. Therefore, we suggest that researchers should perform a more perfect cohort study to get more credible conclusions.

In encapsulated thyroid neoplasms, the presence of capsular invasion is the most important criterion for separating benign neoplasms from malignancy. Currently, capsular invasion is defined in major guidelines as complete penetration of tumor capsules by neoplastic cells (38). Capsular invasion is not rare and has been reported from $9.9 \%$ to $26.8 \%$ of PTC (39). It was reported that capsular invasion is more common in patients with multifocal PTC and is related to tumor recurrence $(33,40)$. In our meta-analysis results, there is no connection between capsular invasion and contralateral occult PTC.

$B R A F$ is a cytoplasmic protein kinase, and it is the main subtype of RAF kinase that could trigger tumorigenesis through the activation of the MAPK pathway. PTC patients with a $B R A F$ mutation are associated with a higher risk of unfavorable clinicopathological characteristics (41). A study of 2,048 patients showed that a $B R A F$ mutation is an independent risk factor for bilateral multifocal PTC $(\mathrm{OR}=1.233,95 \% \mathrm{CI}=1.063-$ $1.431, \mathrm{p}=0.006$ ) (42). However, we found no association between BRAF mutation and contralateral occult PTC. This may be because of the coexistent benign nodules in the contralateral lobe that could have affected the observed rate of contralateral occult carcinoma. The more useful reason may be the limited sample size; we considered that if there is an expanded sample size, the results would be reversed.

HT is the most common autoimmune thyroid disease. It causes the immune system to attack and destroy the thyroid gland and is the most common cause of primary hypothyroidism and nonendemic goiter. Liang et al. reported that PTC patients with HT have a higher rate of multifocality $(\mathrm{p}=0.024)$ than patients without HT (42). This meta-analysis results showed no relation between HT and contralateral occult PTC.
Among the patients with unilateral PTC, a portion of them had contralateral thyroid nodules. A study of 1,442 patients reported that $667(46.95 \%)$ patients with contralateral benign nodules were ultimately confirmed to be PTC (19). The therapeutic strategy for patients in this situation is controversial and challenging. Our data demonstrate that patients with contralateral benign nodules have increased contralateral occult PTC. This result may be because some small foci masked by a benign nodule in the contralateral lobe could lead to incorrect assessment during preoperative US or FNA. Therefore, we suggest that surgeons should evaluate the huge possibility of the presence of contralateral occult carcinoma in PTC patients with contralateral thyroid nodules and to deal with it more actively.

Multifocality might occur through the spread of an original tumor via intraglandular lymphatics. Cancer cells can cause metastasis to the contralateral gland through lymphatic dissemination, as well as lymph node metastasis. It is well established that PTC has a strong propensity for lymph node metastasis. Lymph node metastasis in PTC follows a predictable pattern. Most commonly, tumor cells metastasize to the central lymph node, followed by those of the lateral lymph node. Rarely, some patients develop LLNM in PTC without CLNM (43). It was reported that multifocality increases the risk of CLNM (44). However, the role of multifocality in LLNM remains a topic of debate $(43,45)$. Our results showed that patients with CLNM have more contralateral occult PTC but no significant relationship between LLNM and contralateral occult PTC. This might be because only three studies evaluated LLNM, and we considered that the result would be reversed by bringing in a large sample size research.

There are some limitations to this study. First, all of the studies were conducted in Asian countries. Second, most of the pooled studies were not prospective or randomized case-control trials. Third, the number of included studies was limited, which might have affected the results of our study, especially the risk factor analysis.

\section{CONCLUSION}

The meta-analysis demonstrates the following risk factors for contralateral occult PTC: tumor size $>1 \mathrm{~cm}$, ipsilateral multifocality, contralateral benign nodule, and CLNM. Sex, age, ETE, capsular invasion, BRAF mutation, HT, and LLNM do not affect contralateral occult PTC. Overall, although TT presents complications, the operation should be evaluated and implemented more actively when $\geq 1$ risk factor is found in patients with PTC.

\section{DATA AVAILABILITY STATEMENT}

The original contributions presented in the study are included in the article/supplementary material. Further inquiries can be directed to the corresponding author. 


\section{ETHICS STATEMENT}

The studies involving human participants were reviewed and approved by Medical Science Research Ethics Committee of the First Hospital of China Medical University. Written informed consent for participation was not required for this study in accordance with the national legislation and the institutional requirements.

\section{AUTHOR CONTRIBUTIONS}

FZ is the first author of this study. WT is the corresponding author supervising this work. FZ, BZ, and XW collected the clinical medical records. $\mathrm{FZ}$ and $\mathrm{BZ}$ conceived and designed the meta-analysis. BZ and $\mathrm{XY}$ performed the meta-analysis. FZ

\section{REFERENCES}

1. Siegel RL, Miller KD, Jemal A. Cancer Statistics, 2020. CA Cancer J Clin (2020) 70(1):7-30. doi: 10.3322/caac.21590

2. Powers AE, Marcadis AR, Lee M, Morris LGT, Marti JL. Changes in Trends in Thyroid Cancer Incidence in the United States, 1992 to 2016. JAMA (2019) 322(24):2440-1. doi: 10.1001/jama.2019.18528

3. Hauch A, Al-Qurayshi Z, Randolph G, Kandil E. Total Thyroidectomy Is Associated With Increased Risk of Complications for Low- and High-Volume Surgeons. Ann Surg Oncol (2014) 21(12):3844-52. doi: 10.1245/s10434-0143846-8

4. Yang L, Shen W, Sakamoto N. Population-Based Study Evaluating and Predicting the Probability of Death Resulting From Thyroid Cancer and Other Causes Among Patients With Thyroid Cancer. J Clin Oncol (2013) 31 (4):468-74. doi: 10.1200/JCO.2012.42.4457

5. Lim H, Devesa SS, Sosa JA, Check D, Kitahara CM. Trends in Thyroid Cancer Incidence and Mortality in the United States, 1974-2013. JAMA (2017) 317 (13):1338-48. doi: 10.1001/jama.2017.2719

6. Chen HY, Liu WY, Zhu H, Jiang DW, Wang DH, Chen Y, et al. Diagnostic Value of Contrast-Enhanced Ultrasound in Papillary Thyroid Microcarcinoma. Exp Ther Med (2016) 11(5):1555-62. doi: 10.3892/etm.2016.3094

7. Kuo SF, Lin SF, Chao TC, Hsueh C, Lin KJ, Lin JD. Prognosis of Multifocal Papillary Thyroid Carcinoma. Int J Endocrinol (2013) 2013:809382. doi: $10.1155 / 2013 / 809382$

8. Ng SC, Kuo SF, Chen ST, Hsueh C, Huang BY, Lin JD. Therapeutic Outcomes of Patients With Multifocal Papillary Thyroid Microcarcinomas and Larger Tumors. Int J Endocrinol (2017) 2017:4208178. doi: 10.1155/2017/4208178

9. So YK, Kim MW, Son YI. Multifocality and Bilaterality of Papillary Thyroid Microcarcinoma. Clin Exp Otorhinolaryngol (2015) 8(2):174-8. doi: 10.3342/ ceo.2015.8.2.174

10. Haugen BR, Alexander EK, Bible KC, Doherty GM, Mandel SJ, Nikiforov YE, et al. 2015 American Thyroid Association Management Guidelines for Adult Patients With Thyroid Nodules and Differentiated Thyroid Cancer: The American Thyroid Association Guidelines Task Force on Thyroid Nodules and Differentiated Thyroid Cancer. Thyroid (2016) 26(1):1-133. doi: 10.1089/ thy.2015.0020

11. Wang N, Qian LX. Predictive Factors for Occult Bilateral Papillary Thyroid Carcinoma. Acad Radiol (2021) 28(3):328-32. doi: 10.1016/j.acra.2020.01.023

12. Chen X, Zhong Z, Song M, Yuan J, Huang Z, Du J, et al. Predictive Factors of Contralateral Occult Carcinoma in Patients With Papillary Thyroid Carcinoma: A Retrospective Study. Gland Surg (2020) 9(4):872-8. doi: 10.21037/gs-19-157

13. Wan HF, Zhang B, Yan DG, Xu ZG. The BRAFT1799A Mutation Is Not Associated With Occult Contralateral Carcinoma in Patients With Unilateral performed the statistical analyses of all the data and wrote the manuscript. XW and SW contributed material/analysis tools. FZ and $\mathrm{BZ}$ collected reference and managed the data. FZ and WT designed the study. All authors contributed to the article and approved the submitted version.

\section{FUNDING}

This study was supported by The Research Fund for Public Welfare, National Health and Family Planning Commission of China (grant 201402005). The funder had no role in study design, data collection or analysis, or in the presentation or publication of the results.
Papillary Thyroid Microcarcinoma. Asian Pac J Cancer Prev (2015) 16 (7):2947-51. doi: 10.7314/APJCP.2015.16.7.2947

14. Moher D, Liberati A, Tetzlaff J, Altman DG, Group P. Preferred Reporting Items for Systematic Reviews and Meta-Analyses: The PRISMA Statement. Open Med (2009) 3(3):e123-30.

15. Stang A. Critical Evaluation of the Newcastle-Ottawa Scale for the Assessment of the Quality of Nonrandomized Studies in Meta-Analyses. Eur J Epidemiol (2010) 25(9):603-5. doi: 10.1007/s10654-010-9491-z

16. Feng JW, Ye J, Wu WX, Pan H, Qin AC, Jiang Y, et al. Management of Clinically Solitary Papillary Thyroid Carcinoma Patients According to RiskScoring Model for Contralateral Occult Carcinoma. Front Endocrinol (Lausanne) (2020) 11:553577. doi: 10.3389/fendo.2020.553577

17. Gu JL, Nie XL, Wang WD, Xiang YF, Jiang L, Shang JB. Multifocality of the Primary Tumor Is a Predictive Factor for Contralateral Occult Carcinoma in Patients With Unilateral Papillary Thyroid Carcinoma. Int J Clin Exp Patho (2016) 9(11):11972-7. doi: 10.1089/thy.2015.0315

18. Koo BS, Lim HS, Lim YC, Yoon YH, Kim YM, Park YH, et al. Occult Contralateral Carcinoma in Patients With Unilateral Papillary Thyroid Microcarcinoma. Ann Surg Oncol (2010) 17(4):1101-5. doi: 10.1245/s10434-009-0906-6

19. Lv T, Zhu C, Di Z. Risk Factors Stratifying Malignancy of Nodules in Contralateral Thyroid Lobe in Patients With Pre-Operative Ultrasound Indicated Unilateral Papillary Thyroid Carcinoma: A Retrospective Analysis From Single Centre. Clin Endocrinol (Oxf) (2018) 88(2):279-84. doi: 10.1111/ cen.13506

20. Zhou YL, Zhang W, Gao EL, Dai XX, Yang H, Zhang XH, et al. Preoperative BRAF Mutation Is Predictive of Occult Contralateral Carcinoma in Patients With Unilateral Papillary Thyroid Microcarcinoma. Asian Pac J Cancer Prev (2012) 13(4):1267-72. doi: 10.7314/APJCP.2012.13.4.1267

21. Vaiman M, Nagibin A, Olevson J. Complications in Primary and Completed Thyroidectomy. Surg Today (2010) 40(2):114-8. doi: 10.1007/s00595-008-4027-9

22. Raffaelli M, De Crea C, Sessa L, Giustacchini P, Revelli L, Bellantone C, et al. Prospective Evaluation of Total Thyroidectomy Versus Ipsilateral Versus Bilateral Central Neck Dissection in Patients With Clinically Node-Negative Papillary Thyroid Carcinoma. Surgery (2012) 152(6):957-64. doi: 10.1016/ j.surg.2012.08.053

23. So YK, Seo MY, Son YI. Prophylactic Central Lymph Node Dissection for Clinically Node-Negative Papillary Thyroid Microcarcinoma: Influence on Serum Thyroglobulin Level, Recurrence Rate, and Postoperative Complications. Surgery (2012) 151(2):192-8. doi: 10.1016/j.surg.2011.02.004

24. Nilubol N, Kebebew E. Should Small Papillary Thyroid Cancer be Observed? A population-based study. Cancer (2015) 121(7):1017-24. doi: 10.1002/ cncr. 29123

25. Liu C, Chen T, Zeng W, Wang S, Xiong Y, Liu Z, et al. Reevaluating the Prognostic Significance of Male Gender for Papillary Thyroid Carcinoma and 
Microcarcinoma: A SEER Database Analysis. Sci Rep (2017) 7(1):11412. doi: 10.1038/s41598-017-11788-8

26. Haymart MR. Understanding the Relationship Between Age and Thyroid Cancer. Oncologist (2009) 14(3):216-21. doi: 10.1634/theoncologist.2008-0194

27. Nixon IJ, Wang LY, Migliacci JC, Eskander A, Campbell MJ, Aniss A, et al. An International Multi-Institutional Validation of Age 55 Years as a Cutoff for Risk Stratification in the AJCC/UICC Staging System for Well-Differentiated Thyroid Cancer. Thyroid (2016) 26(3):373-80. doi: 10.1089/thy.2015.0315

28. Lee KJ, Cho YJ, Kim JG, Lee DH. How Many Contralateral Papillary Thyroid Carcinomas can be Missed? World J Surg (2013) 37(4):780-5. doi: 10.1007/ s00268-013-1913-0

29. Zhou YL, Gao EL, Zhang W, Yang H, Guo GL, Zhang XH, et al. Factors Predictive of Papillary Thyroid Micro-Carcinoma With Bilateral Involvement and Central Lymph Node Metastasis: A Retrospective Study. World J Surg Oncol (2012) 10:67. doi: 10.1186/1477-7819-10-67

30. Pitt SC, Sippel RS, Chen H. Contralateral Papillary Thyroid Cancer: Does Size Matter? Am J Surg (2009) 197(3):342-7. doi: 10.1016/j.amjsurg.2008.09.011

31. Hay ID, Hutchinson ME, Gonzalez-Losada T, McIver B, Reinalda ME, Grant CS, et al. Papillary Thyroid Microcarcinoma: A Study of 900 Cases Observed in a 60-Year Period. Surgery (2008) 144(6):980-7; discussion 7-8. doi: 10.1016/j.surg.2008.08.035

32. Zhang L, Wei WJ, Ji QH, Zhu YX, Wang ZY, Wang Y, et al. Risk Factors for Neck Nodal Metastasis in Papillary Thyroid Microcarcinoma: A Study of 1066 Patients. J Clin Endocrinol Metab (2012) 97(4):1250-7. doi: 10.1210/jc.2011-1546

33. Tam AA, Ozdemir D, Cuhaci N, Baser H, Aydin C, Yazgan AK, et al. Association of Multifocality, Tumor Number, and Total Tumor Diameter With Clinicopathological Features in Papillary Thyroid Cancer. Endocrine (2016) 53(3):774-83. doi: 10.1007/s12020-016-0955-0

34. Joseph KR, Edirimanne S, Eslick GD. Multifocality as a Prognostic Factor in Thyroid Cancer: A Meta-Analysis. Int J Surg (2018) 50:121-5. doi: 10.1016/ j.ijsu.2017.12.035

35. Ortiz S, Rodriguez JM, Soria T, Perez-Flores D, Pinero A, Moreno J, et al. Extrathyroid Spread in Papillary Carcinoma of the Thyroid: Clinicopathological and Prognostic Study. Otolaryngol Head Neck Surg (2001) 124(3):261-5. doi: 10.1067/mhn.2001.113141

36. Jin BJ, Kim MK, Ji YB, Song CM, Park JH, Tae K. Characteristics and Significance of Minimal and Maximal Extrathyroidal Extension in Papillary Thyroid Carcinoma. Oral Oncol (2015) 51(8):759-63. doi: 10.1016/ j.oraloncology.2015.05.010

37. Feng JW, Qu Z, Qin AC, Pan H, Ye J, Jiang Y. Significance of Multifocality in Papillary Thyroid Carcinoma. Eur J Surg Oncol (2020) 46(10 Pt A):1820-8. doi: 10.1016/j.ejso.2020.06.015
38. Haugen BR, Sawka AM, Alexander EK, Bible KC, Caturegli P, Doherty GM, et al. American Thyroid Association Guidelines on the Management of Thyroid Nodules and Differentiated Thyroid Cancer Task Force Review and Recommendation on the Proposed Renaming of Encapsulated Follicular Variant Papillary Thyroid Carcinoma Without Invasion to Noninvasive Follicular Thyroid Neoplasm With Papillary-Like Nuclear Features. Thyroid (2017) 27(4):481-3. doi: 10.1089/thy.2016.0628

39. Li M, Zhu XY, Lv J, Lu K, Shen MP, Xu ZL, et al. Risk Factors for Predicting Central Lymph Node Metastasis in Papillary Thyroid Microcarcinoma (CN0): A Study of 273 Resections. Eur Rev Med Pharmacol Sci (2017) 21(17):3801-7.

40. Giordano D, Gradoni P, Oretti G, Molina E, Ferri T. Treatment and Prognostic Factors of Papillary Thyroid Microcarcinoma. Clin Otolaryngol (2010) 35(2):118-24. doi: 10.1111/j.1749-4486.2010.02085.x

41. Zhang Q, Liu SZ, Zhang Q, Guan YX, Chen QJ, Zhu QY. Meta-Analyses of Association Between BRAF(V600E) Mutation and Clinicopathological Features of Papillary Thyroid Carcinoma. Cell Physiol Biochem (2016) 38 (2):763-76. doi: 10.1159/000443032

42. Yan C, Huang M, Li X, Wang T, Ling R. Relationship Between BRAF V600E and Clinical Features in Papillary Thyroid Carcinoma. Endocr Connect (2019) 8(7):988-96. doi: 10.1530/EC-19-0246

43. Liang J, Zeng W, Fang F, Yu T, Zhao Y, Fan X, et al. Clinical Analysis of Hashimoto Thyroiditis Coexistent With Papillary Thyroid Cancer in 1392 Patients. Acta Otorhinolaryngol Ital (2017) 37(5):393-400. doi: 10.14639/ 0392-100X-1709

44. Al Afif A, Williams BA, Rigby MH, Bullock MJ, Taylor SM, Trites J, et al. Multifocal Papillary Thyroid Cancer Increases the Risk of Central Lymph Node Metastasis. Thyroid (2015) 25(9):1008-12. doi: 10.1089/ thy.2015.0130

45. Hu D, Zhou J, He W, Peng J, Cao Y, Ren H, et al. Risk Factors of Lateral Lymph Node Metastasis in cN0 Papillary Thyroid Carcinoma. World J Surg Oncol (2018) 16(1):30. doi: 10.1186/s12957-018-1336-3

Conflict of Interest: The authors declare that the research was conducted in the absence of any commercial or financial relationships that could be construed as a potential conflict of interest.

Copyright $\odot 2021$ Zhang, Zheng, Yu, Wang, Wang and Teng. This is an open-access article distributed under the terms of the Creative Commons Attribution License (CC BY). The use, distribution or reproduction in other forums is permitted, provided the original author(s) and the copyright owner(s) are credited and that the original publication in this journal is cited, in accordance with accepted academic practice. No use, distribution or reproduction is permitted which does not comply with these terms. 